\title{
Free Radical Polymerization of Methyl and Ethyl Methacrylates by Green Methodology
}

\author{
Dr. M. Meena \\ Department of $S$ \& H (Chemistry), R. M. K. Engineering College, \\ Thiruvallur District, Tamil Nadu, India. \\ Dr. S. Nanjundan \\ Department of Chemistry, PERI Institute of Technology, \\ Tamil Nadu, Chennai, India. \\ Dr. M. J. Umapathy \\ Department of Chemistry, Anna University, \\ Tamil Nadu, Chennai, India.
}

\begin{abstract}
The efficiency of newly synthesized single site phase transfer catalyst has been studied with the help of kinetics of free radical polymerization of methyl and ethyl methacrylate (MMA and EMA). The radical polymerization was catalyzed with single site phase transfer catalyst, 2benzoylethyldecyldimethylammo-nium bromide (BEDDAB) and initiated by water soluble potassium peroxydisulphate initiator in ethyl acetate / water biphase media under inert condition at constant temperature $60 \pm 1^{\circ} \mathrm{C}$. The prepared phase transfer catalyst has been characterized by FT-IR, ${ }^{1} \mathrm{H}-\mathrm{NMR}$ and ${ }^{13} \mathrm{C}$-NMR as well as $\mathrm{C}, \mathrm{H}$ and $\mathrm{N}$ elemental analysis. The order of the reaction with respect to monomer, initiator, phase transfer catalyst (PTC) and temperature was ascertained. A suitable kinetic mechanism has been proposed as per the experimental conditions. Molecular weight of the polymethyl methacrylate (PMMA) as well as polyethylmethacrylate (PEMA) which have been polymerized using phase transfer catalyst was evaluated using GPC technique.
\end{abstract}

Keywords: Single sitephase transfer catalyst; 2Benzoylethyldecyldimethylammonium bromide; Kinetic mechanism; Radical polymerization.

\section{Introduction}

Rapid industrialization and revolution has focused significant attention on green chemistry. Among the new developments in the organic synthesis towards green technology, reactions involving phase transfer catalyst has become a versatile technique because of its mild reaction conditions, large conversion and product selectivity [1-3]. Though the reaction between hydrophilic and lipophilic reactants can be facilitated by appropriate aprotic solvent, the separation of solvent from the reaction mixture and the cost has established the phase transfer catalyst as a power tool in bringing plausible reaction between two mutually immiscible phases. The first published biphasic method for the generation of dichlorocarbene by Makosza [4] has triggered and propelled the application of phase transfer catalyst in organic synthesis. Hence it has become a fascinating area of research. Researchers studied the success of single site phase transfer catalystespecially in free radical vinyl monomers involving aqueous-organic biphase media [5-17]. These studies provoked us to check the efficiency of a newly synthesized single-site phase transfer catalyst by polymerizingMMA and EMA and its competency has been analyzed bykinetic study using water soluble potassium peroxydisulphate(PDS) initiator.

\section{Experimental Details \\ Materials and Methods}

The monomers methyl methacrylate and ethyl methacrylate (Merck, Mumbai) were subjected to reduced pressure distillation before use. The water soluble initiator, potassium peroxydisulphate (SRL, Mumbai) was used as such. Methanol (SRL, Mumbai) was distilled over a water bath and used. Formaldehyde (SRL Mumbai) was used as received. Dimethyl amine (Merck) acetophenone (Merck) ethyl acetate (SRL, Mumbai) were distilled before use. Double distilled water was used as solvent for the biphase system.

\section{Instrumentation}

The FT-IR spectrum was recorded on a Perkin Elmer RX I spectrometer in the spectral region from 4400 to $400 \mathrm{~cm}^{-1}$ using $\mathrm{KBr}$. High resolution ${ }^{1} \mathrm{H}-\mathrm{NMR}$ spectra and ${ }^{13} \mathrm{C}-\mathrm{NMR}$ spectra was recordedon a Bruker500 $\mathrm{MHz}$ and Bruker DRX 125.77 MHz FT-NMR spectrometersat room temperature using $\mathrm{D}_{2} \mathrm{O}$ solvent. Molecular weight of the polymer was determined by Waters 501 gel permeation chromatograph. Tetrahydrofuran was used as an eluent and polystyrene standards were employed for calibration. The glass transition temperature was determined with a Perkin-Elmer DSC-7 differential scanning calorimeter at a heating rate of $10^{\circ} \mathrm{C} / \mathrm{min}$ in $\mathrm{N}_{2}$ atmosphere.

\footnotetext{
Synthesis of 2-Benzoylethyldecyldimethylammonium bromide (BEDDAB)

Single site phase transfer catalyst was prepared in two stages. In the first stage dimethylaminepropiophenone hydrochloride was prepared as reported in the literature [18] by treating equal moles $(0.33$ mole $)$ of dry methylamine, powdered para
} 
formaldehyde and acetophenone and40 $\mathrm{ml}$ of $95 \%$ ethanol containing $0.5 \mathrm{ml}$ of con. $\mathrm{HCl}$.

In the second stage 0.28 mole of the prepared dimethylaminepropiophenone hydrochloride was taken in a separating funnel and mixed with ether. Then $100 \mathrm{ml}$ of sodium bicarbonate $(0.1 \mathrm{~N})$ solution was added little by little and the separation funnel was shaken from time to time. The free amine, dimethylaminepropiophenone was extracted in ether. The ether layer containing the amine was quaternized by the addition of 0.28 mole of n-bromodecane in cold conditions. The product was allowed to stand overnight in a closed vessel and then filtered. The obtained product was purified by recrystallization using acetone-alcohol mixture.

After being dried in a vacuum at $60^{\circ} \mathrm{C}$ for $24 \mathrm{hrs}$, the purified 2-benzoylethyldecyldimethylammonium bromide (BEDDAB) was collected. The yield in the second stage was $90 \%$. The synthesis of BEDDAB is shown in Scheme 1

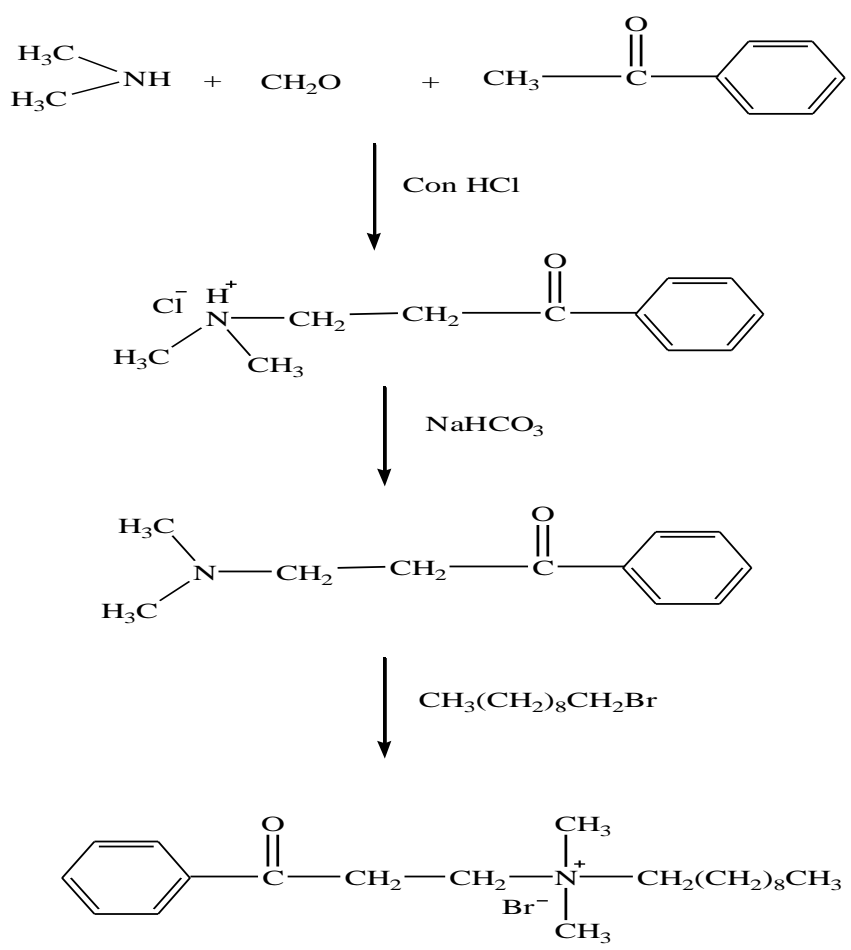

$\begin{array}{lcc}\text { Scheme } & 1 . & \text { Synthesis } \\ \text { Benzoylethyldecyldimethylammonium bromide }\end{array}$

\section{Polymerization Procedure}

A typical polymerization of the monomers, methyl methacrylate (MMA) and ethylmethacrylate (EMA) was carried out using a long closed Pyrex tube under unstirred, inert atmospheric conditions at $60 \pm 1^{\circ} \mathrm{C}$. The reaction mixture consists of monomerin $10 \mathrm{ml}$ organic phase (ethyl acetate) and the phase transfer catalyst (BEDDAB), sodium bisulphate $(0$. 5 mole $\mathrm{dm}^{-3}$ ) for adjusting the ionic strength and sulphuric acid $\left(0.2 \mathrm{~mol} \mathrm{dm}^{-3}\right)$ for maintaining the $\mathrm{pH}$ in $10 \mathrm{ml}$ ofaqueous phase.

Polymerization reaction was initiated by the addition of potassium peroxydisulphate (PDS) to the reaction mixture. After stipulated time, the reaction was arrested by pouring the reaction mixture into ice cold methanol $[5-9,12,13,17]$. The precipitated polymer was filtered through a sintered glass crucible, washed with double distilled water and methanol and then dried in oven $\left(60 \pm 0.1^{\circ} \mathrm{C}\right)$ until constant weight was obtained. The rate of polymerization $(\mathrm{Rp})$ was calculated using equation (1).

$$
R p=\frac{1000 \times W}{V \times t \times M}-\cdots-\cdots-\cdots(1)
$$

Where Rp-Rate of Polymerization; W-Weight of polymer in grams, V-Volume of reaction mixture; t-Reaction time in seconds; M-Molecular weight of the monomer.

\section{Results and Discussion \\ Synthesis of 2-Benzoylethyldecyldimethylammonium bromide (BEDDAB)}

In the first stage dimethylaminepropiophenone hydrochloride was prepared by condensing dimethylamine and acetophenone with formaldehyde in the presence of conc. $\mathrm{HCl}$ at slightly warm conditions.

The dimethylaminepropiophenone hydrochloride was then neutralized by treating with sodium bicarbonate to isolate dimethylaminepropiophenone which was extracted with ether. The amine was then quaternized by the addition of $n$ bromodecane in cold conditions. Thus the obtained product was purified by recrystallization using acetone-alcohol mixture. After being dried in a vacuum at $60^{\circ} \mathrm{C}$ for $24 \mathrm{hrs}$, the purified 2-benzoylethyldecyldimethylammonium bromide was collected. The synthesis of BEDDAB is shown in Scheme1.

\section{Characterization of $B E D D A B$ \\ $F T-I R$ spectral analysis of $B E D D A B$}

TheFT-IR spectrum of BEDDAB is shown in Fig 1:3401 $\mathrm{cm}^{-1}$ (over tone of carbonyl group), $3068 \mathrm{~cm}^{-1}$ (aromatic $=\mathrm{C}-\mathrm{H}$ stretching), 2987, $2965 \mathrm{~cm}^{-1}$ (symmetrical, asymmetrical C-H stretching), $1720 \mathrm{~cm}^{-1}(>\mathrm{C}=\mathrm{O}$ stretching $), 1597,1508$ and $1445 \mathrm{~cm}^{-1}$ (C=C stretching vibrations of the ring), $1459 \mathrm{~cm}^{-1}$ (- $\mathrm{CH}_{2}-\mathrm{N}$ stretching), $1377 \mathrm{~cm}^{-1}\left(-\mathrm{CH}_{3}-\mathrm{N}\right.$ stretching), $932 \mathrm{~cm}^{-1}$ (due to rocking of- $\mathrm{CH}_{2}$ group), 922 and $747 \mathrm{~cm}^{-1}$ (C-H out of plane bending vibrations of the aromatic nuclei).

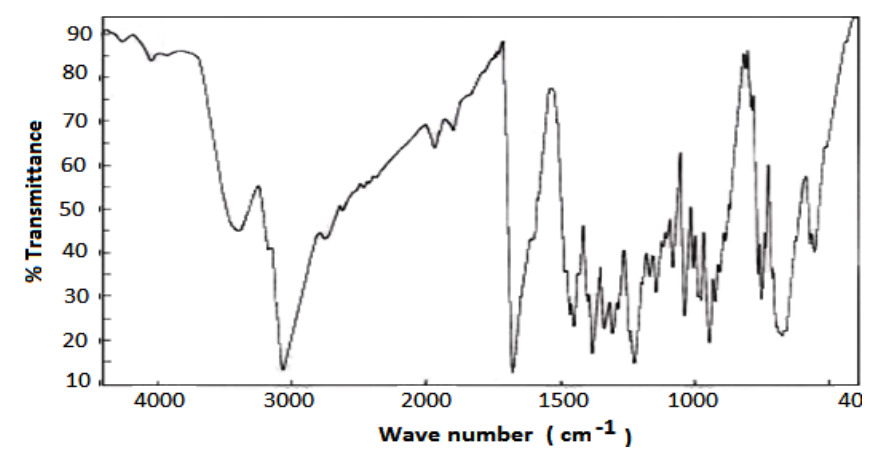

Figure 1. FT-IR Spectrum of BEDDAB

${ }^{1} \mathrm{H}-\mathrm{NMR}$ spectral analysis of BEDDAB

${ }^{1} \mathrm{H}-\mathrm{NMR}$ spectrum ofBEDDAB is shown in Fig.2. 
Thefollowing resonance signals were observed for BEDDAB: 7.57, 7.43 and $7.34 \mathrm{ppm}$ (aromatic protons), 2.91 and 2.76 ppm (methylene groups attached to the carbonyl carbon and the nitrogen atom respectively), $2.53 \mathrm{ppm}$ (methylene group of the decyl group which is attached to the nitrogen atom), 2.33 and $2.25 \mathrm{ppm}$ (proton signals due to the methyl groups attached to the nitrogen atom), $0.95 \mathrm{ppm}$ (methyl protons of the decyl group), 1.64 and $1.21 \mathrm{ppm}$ (other methylene protons of the decyl group).

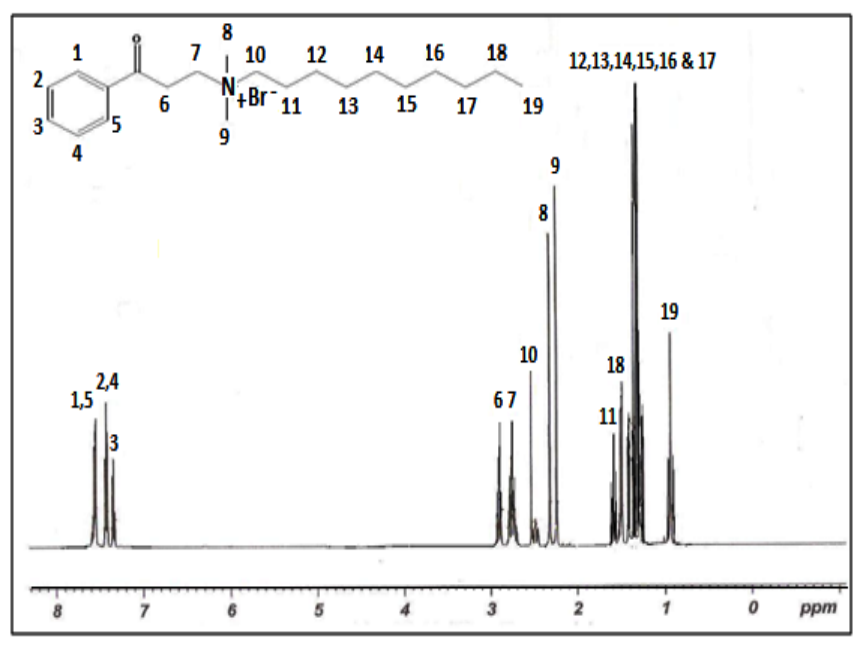

Figure 2. ${ }^{1} \mathrm{H}-\mathrm{NMR}$ Spectrum of BEDDAB

\section{${ }^{13}$ C-NMR spectral analysisof $B E D D A B$}

${ }^{13} \mathrm{C}$-NMR spectrum of BEDDAB was shown in Fig.3. The following resonance signals were observed in the spectra: 200.62 ppm (carbonyl carbon), 136.24, 133.96, 128.96 and $128.88 \mathrm{ppm}$ (aromatic carbons), 59.74 and $57.02 \mathrm{ppm}$ (methylene carbons attached to the nitrogen atom), $43.04 \mathrm{ppm}$ (methylene carbon attached to the carbonyl carbon), 46.91 ppm (methyl carbons attached to the nitrogen atom), 14.11 ppm (methyl carbon of the decyl group), 33.49, 30.94, 30.14, 28.31, 27.23 and $23.12 \mathrm{ppm}$ (other methylene carbons of the decyl group)

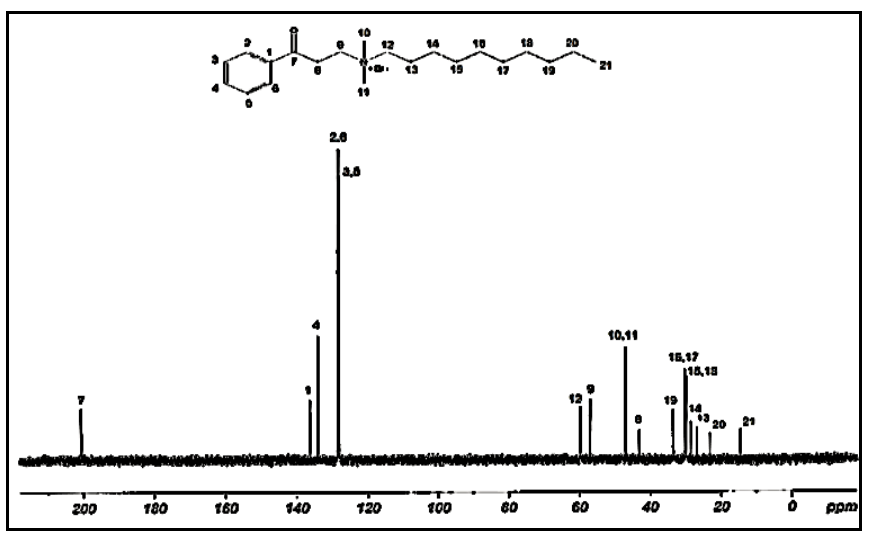

Figure 3. ${ }^{13} \mathrm{C}-\mathrm{NMR}$ Spectrum of BEDDAB

Elemental analysisof $\mathrm{BEDDAB}$

Carbon, Hydrogen and Nitrogen contents of BEDDAB has been analyzed and the results are very close to the theoretical values.

Molecular Formula: $\mathrm{C}_{21} \mathrm{H}_{36} \mathrm{BrNO}$; Mol.Wt.: 398; Elemental analysis (\%): C: 63.27 (Found): 63.31 (Calculated), H: 9.13

(Found): 9.11 (Calculated), N: 3.49 (Found): 3.52 (Calculated).

\section{The Kinetics of Free Radical Polymerization}

The kinetics of free radical polymerization of methyl and ethyl methacrylate using BEDDAB as catalyst and PDS as initiator under ethyl acetate / water biphase media was studied under following experimental conditions.

\section{Steady state rate of polymerization}

The rate of polymerization of the monomers was ascertained by keeping the concentration of monomeras 2.0 mole $\mathrm{dm}^{-3}$ and PDS as $2.0 \times 10^{-2}$ mole $\mathrm{dm}^{-3}$, volume of aqueous and organic phase as $10 \mathrm{ml}$, the concentration of sulphuric acid as 0.2 mole $\mathrm{dm}^{-3}$, concentration of sodium bisulphate as 0.5 mole $\mathrm{dm}^{-3}$ and the polymerization was started by adding $1.0 \times 10^{-1}$ mole $\mathrm{dm}^{-}$ ${ }^{3}$ of BEDDAB to the aqueous phase. Table 1 shows the rate of polymerization of MMA and EMA at different time intervals.

Table 1. Steady state rate of polymerization $[\mathrm{BEDDAB}]=1.0$ x $10^{-1} \mathrm{~mol} \mathrm{dm}^{-3}$; [Monomer] $=2.0 \mathrm{~mol} \mathrm{dm}^{-3}\left[\mathrm{H}_{2} \mathrm{SO}_{4}\right]=0.2 \mathrm{~mol}$ $\mathrm{dm}^{-3} ;\left[\mathrm{NaHSO}_{3}\right]=0.5 \mathrm{~mol} \mathrm{dm}^{-3} ;[\mathrm{PDS}]=2.0 \times 10^{-2} \mathrm{~mol} \mathrm{dm}^{-3}$

\begin{tabular}{|c|c|c|}
\hline $\begin{array}{c}\text { Time, } \\
\text { minutes }\end{array}$ & $\begin{array}{c}\mathrm{Rp} \times 10^{-5}, \mathrm{~mol} \mathrm{dm} \mathrm{dm}^{-3} \mathrm{~S}^{-1} \\
(\mathrm{MMA})\end{array}$ & $\begin{array}{c}\mathrm{Rp} \times 10^{-5}, \mathrm{~mol} \mathrm{dm} \mathrm{dm}^{-3} \mathrm{~S}^{-} \\
(\mathrm{EMA})\end{array}$ \\
\hline 10 & 5.2092 & 3.5686 \\
\hline 20 & 3.1870 & 2.5295 \\
\hline 30 & 2.1668 & 1.6985 \\
\hline 40 & 1.7042 & 1.2593 \\
\hline 50 & 1.5614 & 1.1344 \\
\hline 60 & 1.5009 & 1.1301 \\
\hline
\end{tabular}

Fig. 4 shows the plot of rate of polymerization versus time intervals. The steady state rate of polymerization was arrived from the plot and it has been fixed as 50 minutes for both methyl methacrylate and ethyl methacrylate using BEDDAB as PTC.

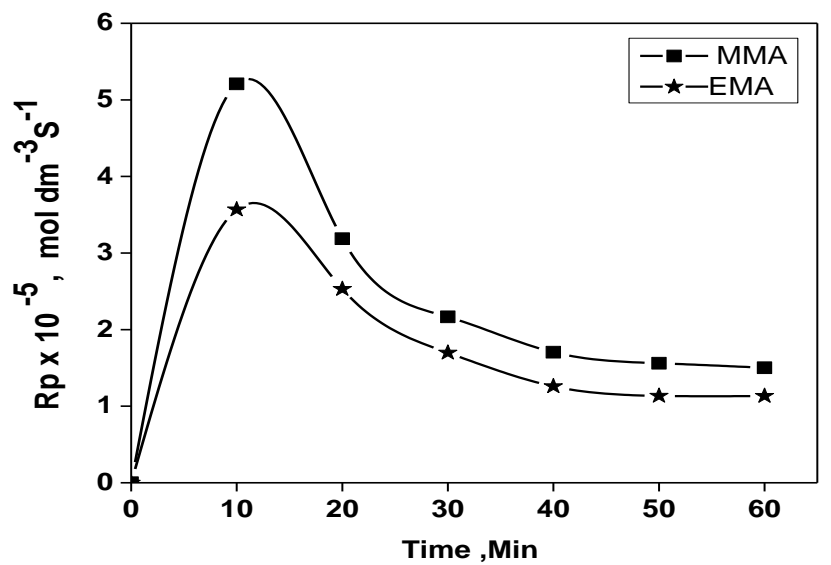

Figure 4. Plot of rate of polymerization vs. Time 


\section{Effect of monomer concentration on $R p$}

The effect of monomer concentration on the rate of polymerization was studied by varying the concentration in the range of 0.8 to 1.8 mole $\mathrm{dm}^{-3}$ by keeping the concentration of PDS as 0.02 mole $\mathrm{dm}^{-3}$, PTC as 0.1 mole $\mathrm{dm}^{-3}$, ionic strength as 0.5 moledm ${ }^{-3}$ and $\mathrm{pH}$ as constant. Table 2 shows the variation of in $\mathrm{Rp}$ with increase in concentrations of the monomers. It was found that the Rp increases with increase in the concentration of monomers.

Table 2. Dependence of Rp on [RMA] in RMA-BEDDAB$\mathrm{K}_{2} \mathrm{~S}_{2} \mathrm{O}_{8}[\mathrm{PDS}]=2.0 \times 10^{-2} \mathrm{~mol} \mathrm{dm}^{-3} ;$ [BEDDAB] $=1.0 \times 10^{-1}$ $\mathrm{mol} \mathrm{dm}{ }^{-3}\left[\mathrm{H}_{2} \mathrm{SO}_{4}\right]=0.2 \mathrm{~mol} \mathrm{dm}^{-3} ;\left[\mathrm{NaHSO}_{3}\right]=0.5 \mathrm{~mol} \mathrm{dm}{ }^{-3}$

\begin{tabular}{|c|c|c|c|c|c|c|}
\hline $\begin{array}{c}\text { RMA]mol } \\
\mathrm{dm}^{-3}\end{array}$ & $\begin{array}{c}\mathrm{RMA}^{0} \\
5 \\
\text { moldm } \\
3\end{array}$ & $\begin{array}{c}\mathrm{Rp} \times 10^{-} \\
5 \mathrm{~mol} \\
\mathrm{~mm}^{-3} \mathrm{~S}^{-1} \\
\mathrm{MMA}^{-1}\end{array}$ & $\begin{array}{c}\mathrm{Rp} \times 10^{-} \\
\mathrm{moldm}^{-3} \\
\mathrm{~S}^{-1} \mathrm{EMA}\end{array}$ & $\begin{array}{l}3+\log \\
{[\mathrm{RMA}]}\end{array}$ & $\begin{array}{c}6+\log \\
\mathrm{Rp} \\
\mathrm{MMA})\end{array}$ & $\begin{array}{c}6+\log \\
\mathrm{Rp} \\
(\mathrm{EMA})\end{array}$ \\
\hline 0.8 & 0.8944 & 1.1712 & 0.6511 & 2.9031 & 1.0686 & 0.8136 \\
\hline 1.0 & 1.0000 & 1.3578 & 0.7139 & 3.0000 & 1.1328 & 0.8536 \\
\hline 1.2 & 1.1055 & 1.4692 & 0.8034 & 3.0790 & 1.1671 & 0.9049 \\
\hline 1.4 & 1.2033 & 1.5465 & 0.8563 & 3.1460 & 1.1893 & 0.9326 \\
\hline 1.6 & 1.2950 & 1.6417 & 0.8636 & 3.2040 & 1.2153 & 0.9363 \\
\hline 1.8 & 1.3817 & 1.6826 & 0.9547 & 3.2550 & 1.2260 & 0.9798 \\
\hline
\end{tabular}

The order of the reactions with respect to variations in concentration of monomers was determined from the slope by plotting log Rp versus log [monomer] as shown in Fig 5. The reaction orders with respect to monomer concentration for MMA and EMA were nearly half order. Also Fig 6 shows the plot of Rp versus concentration of monomer raised to suitable power passes through the origin in each case, which confirms the above observation with respect to [RMA].

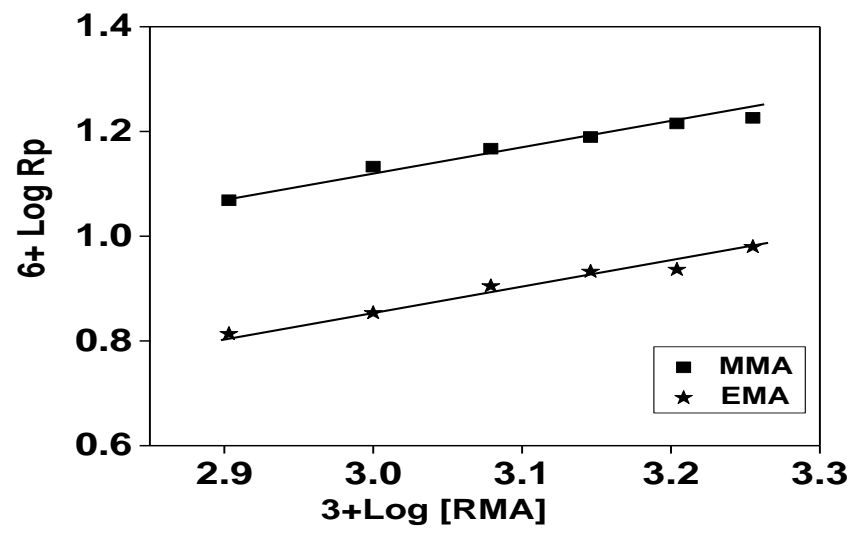

Figure 5. Plot of log Rp vs. $\log [\mathrm{RMA}]$

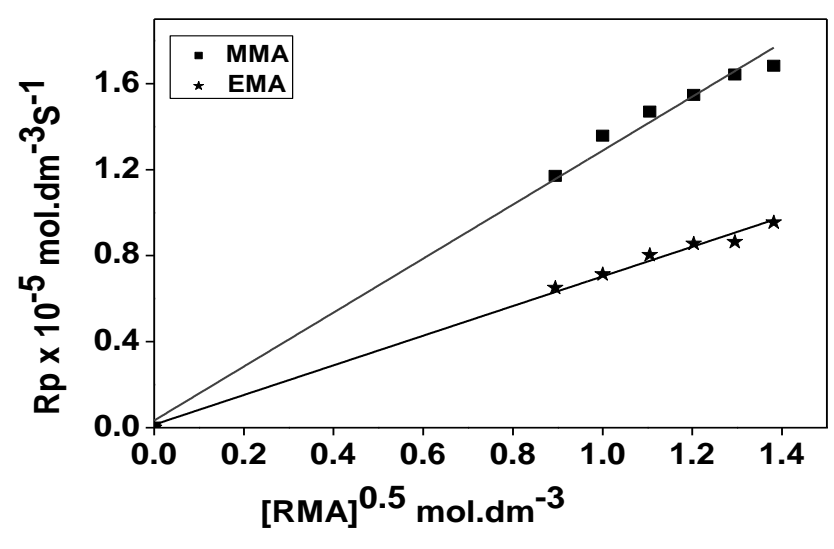

Figure 6. Plot of [RMA ${ }^{0.5} \mathrm{VsRp}$

In the case of free radical polymerization of vinyl monomers, the order with respect to monomer is found to be 1 . 0 . The deviation from the first order [19-21] with respect to monomer may be attributed to any one of the factors such as concentration of monomer involved in the initiation step, primary radical termination and occlusion phenomenon or gel effect.

\section{Effect of initiator concentration on $R p$}

The effect of concentration of $\mathrm{K}_{2} \mathrm{~S}_{2} \mathrm{O}_{8}$ on the rate of polymerization of RMA were studied by varying the concentration of $\mathrm{K}_{2} \mathrm{~S}_{2} \mathrm{O}_{8}$ in the range of 0.015 to 0.025 mole $\mathrm{dm}^{-3}$ by keeping the concentrations of monomer as 2.0 mole $\mathrm{dm}^{-3}$, catalyst as 0.1 mole $\mathrm{dm}^{-3}$ and at constant ionic strength, $\mathrm{pH}$ and volume ratio of aqueous to organic phase. As the concentration of PDS was increased (Table 3), Rp was found to increase. Fig 7 shows the plot of $\log \mathrm{Rp}$ versus $\log$ $\left[\mathrm{K}_{2} \mathrm{~S}_{2} \mathrm{O}_{8}\right]$, the order of reaction was found to be nearly unity forMMA [22, 23] and 0.7 for EMA. Fig 8 and Fig 9 show that, the plot of $\mathrm{Rp}$ versus $\left[\mathrm{K}_{2} \mathrm{~S}_{2} \mathrm{O}_{8}\right]$ for MMA and EMA is linear and the line passed through the origin which confirms above observation. In the case of free radical polymerization of vinyl monomers, the order with respect to initiator is found to be square root of initiator concentration when the polymer radical terminates by mutual bimolecular reaction.

Table 3. Dependence of Rp on $\left[\mathrm{K}_{2} \mathrm{~S}_{2} \mathrm{O}_{8}\right]$ in RMA-BEDDAB$\mathrm{K}_{2} \mathrm{~S}_{2} \mathrm{O}_{8}$ [Monomer] $=2.0 \mathrm{~mol} \mathrm{dm}{ }^{-3}$; [BEDDAB] $=1.0 \times 10^{-1} \mathrm{~mol}$ $\mathrm{dm}^{-3} ;\left[\mathrm{H}_{2} \mathrm{SO}_{4}\right]=0.2 \mathrm{~mol} \mathrm{dm}{ }^{-3} ;\left[\mathrm{NaHSO}_{3}\right]=0.5 \mathrm{~mol} \mathrm{dm}^{-3}$;

\begin{tabular}{|c|c|c|c|c|c|c|}
\hline $\begin{array}{c}{\left[\mathrm{S}_{2} \mathrm{O}_{8}{ }^{2-}\right.} \\
] \\
\text { moldm } \\
3\end{array}$ & $\begin{array}{c}\mathrm{Rp} \times 10^{-} \\
5 \mathrm{moldm} \\
{ }^{3} \mathrm{~S}^{-} \\
{ }^{1} \mathrm{MMA}\end{array}$ & $\begin{array}{c}{\left[\mathrm{S}_{2} \mathrm{O}_{8}{ }^{2-}\right.} \\
]^{0.7} \mathrm{~mol}^{-1} \\
\mathrm{dm}^{-} \\
{ }^{3} \mathrm{EMA}\end{array}$ & $\begin{array}{c}\mathrm{Rp} \times 10^{-} \\
{ }^{5} \text { moldm } \\
{ }^{3} \mathrm{~S}^{-1} \\
\text { EMA }\end{array}$ & $\begin{array}{c}3+\log \left[\mathrm{S}_{2} \mathrm{O}_{8}^{2}\right. \\
]\end{array}$ & $\begin{array}{c}6+\log \\
\text { RpMMA }\end{array}$ & $\begin{array}{c}6+\log \\
\text { Rp } \\
\text { EMA }\end{array}$ \\
\hline 0.015 & 1.4503 & 0.0528 & 0.6511 & 1.1761 & 1.1615 & 0.8027 \\
\hline 0.017 & 1.5523 & 0.0577 & 0.6382 & 1.2304 & 1.1909 & 0.8087 \\
\hline 0.019 & 1.8332 & 0.0624 & 0.6860 & 1.2788 & 1.2632 & 0.8363 \\
\hline 0.021 & 1.8707 & 0.0669 & \begin{tabular}{|l|}
0.7387 \\
\end{tabular} & 1.3222 & 1.2721 & 0.8684 \\
\hline 0.023 & 1.9373 & 0.0713 & 0.8352 & 1.3617 & 1.2872 & 0.9217 \\
\hline 0.025 & 2.3784 & 0.0756 & \begin{tabular}{|l}
0.8921 \\
\end{tabular} & 1.3979 & 1.3763 & 0.9504 \\
\hline
\end{tabular}


The higher order of polymerization in the case of MMA may be either due to the induced decomposition of the initiator or due to the decrease in termination rate constant [24].

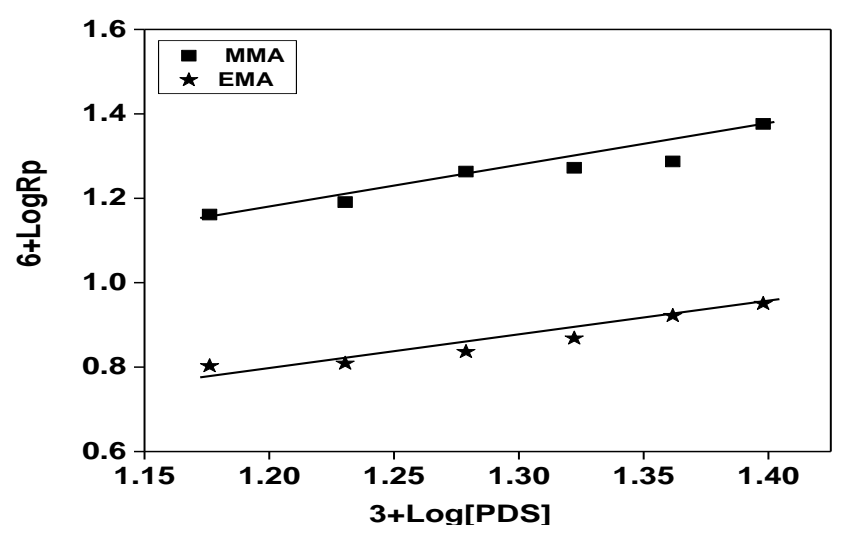

Figure 7. Plot of log Rpvs. log [PDS]

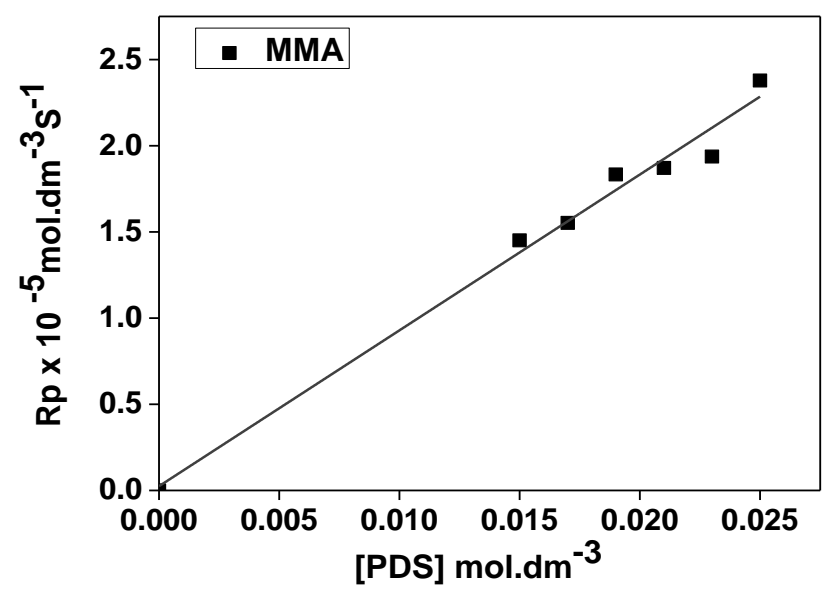

Figure 8. Plot of [PDS] VsRp for MMA

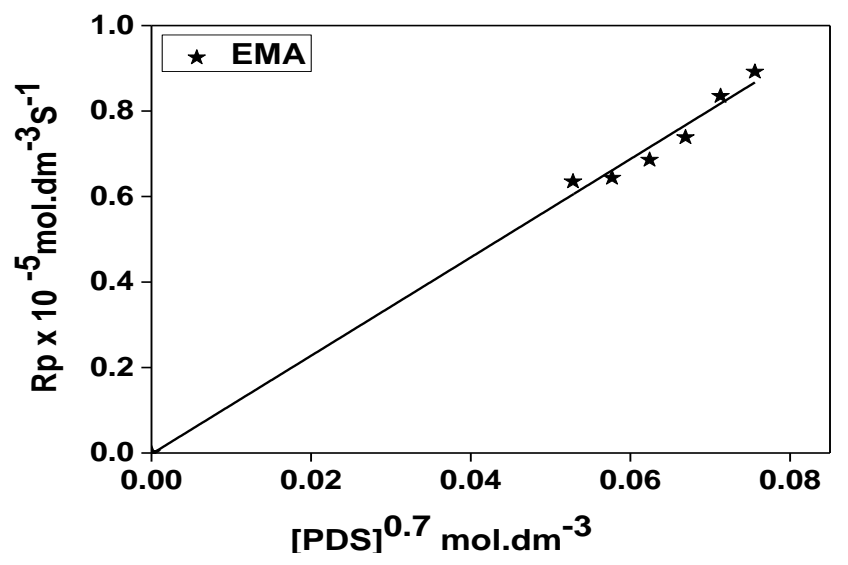

Figure 9. Plot of [PDS] VsRp for EMA

The induced decomposition of peroxydisulphate in the presence of oxidizable organic compounds is well known. The decomposition of PDS in water was greatly enhanced [25, 26] in the presence of methanol, ethanol, ethyl acetate etc. The
$\mathrm{SO}_{4}{ }^{-}$ion generated in the primary decompositioneven attacks theorganiccompoundsabstractingaproton from it forming $\mathrm{HSO}_{4}{ }^{-}$and carbon centered free radicals such as ${ }^{\circ} \mathrm{CH}_{2} \mathrm{OH}$ in the case of methanol and $\mathrm{CH}_{3} \mathrm{COO}^{\circ} \mathrm{CHCH}_{3}$ and $\mathrm{CH}_{3} \mathrm{COOCH}_{2}{ }^{\circ} \mathrm{CH}_{2}$ in case of ethyl acetate.

\section{Effect of concentration of BEDDAB on Rp}

At fixed concentration of other parameters, the effect of [BEDDAB] on $\mathrm{Rp}$ was determined by varying its concentration in the range of $0.015-0.025$ mole $\mathrm{dm}^{-3}$. Table 4 shows that $\mathrm{Rp}$ increased with increase in concentration initially but there observed a slight decrease in $\mathrm{Rp}$ at higher concentration.

Table 4. Dependence of Rp on [PTC] in RMA-BEDDAB$\mathrm{K}_{2} \mathrm{~S}_{2} \mathrm{O}_{8}$ [Monomer] $=2.0 \mathrm{~mol} \mathrm{dm}{ }^{-3} ;$ [PDS] $=2.0 \times 10^{-2} \mathrm{~mol}$ $\mathrm{dm}^{-3} ;\left[\mathrm{H}_{2} \mathrm{SO}_{4}\right]=0.2 \mathrm{~mol} \mathrm{dm}^{-3} ;\left[\mathrm{NaHSO}_{3}\right]=0.5 \mathrm{~mol} \mathrm{dm}^{-3}$;

\begin{tabular}{|c|c|c|c|c|c|c|}
\hline $\begin{array}{c}{[\text { PTC }] \text { mol }} \\
\mathrm{dm}^{-3}\end{array}$ & $\begin{array}{c}{[\mathrm{PTC}]^{0.5} \mathrm{~mol}} \\
\mathrm{dm}^{-3}\end{array}$ & $\begin{array}{c}\mathrm{Rp} \times \\
10^{-5} \mathrm{~mol} \\
\mathrm{dm}^{-3} \mathrm{~S}^{-} \\
{ }^{1} \mathrm{MMA}^{-}\end{array}$ & $\begin{array}{c}\mathrm{Rp} \times \\
10^{-} \\
\mathrm{mmol}^{-3} \mathrm{~S}^{-} \\
\mathrm{dm}^{1} \mathrm{EMA}\end{array}$ & $\begin{array}{c}3+\log \\
{[\mathrm{BEDDAB}]}\end{array}$ & $\begin{array}{c}6+\log \\
\mathrm{RpMMA}\end{array}$ & $\begin{array}{c}6+\log \\
\mathrm{Rp} \\
\mathrm{EMA}\end{array}$ \\
\hline 0.015 & 0.1225 & 1.6699 & 0.6300 & 1.1761 & 1.2227 & 0.7993 \\
\hline 0.017 & 0.1304 & 1.7344 & 0.6556 & 1.2304 & 1.2391 & 0.8166 \\
\hline 0.019 & 0.1378 & 1.8231 & 0.6860 & 1.2788 & 1.2608 & 0.8363 \\
\hline 0.021 & 0.1449 & 2.0101 & 0.7521 & 1.3222 & 1.3032 & 0.8763 \\
\hline 0.023 & 0.1517 & 1.8272 & 0.7351 & 1.3617 & 1.2618 & 0.8663 \\
\hline 0.025 & 0.1581 & 1.8187 & 0.7345 & 1.3979 & 1.2598 & 0.8609 \\
\hline
\end{tabular}

A leveling off tendency was shown at higher concentration. Thesame leveling off tendency was also reported $[27,28]$ when the concentration of PTC reached maximum in the radical polymerization of alkyl methacrylates using potassium peroxomonosulphate as initiator.

Fig 10 shows the order with respect to the concentration of the catalyst which was found to be around 0.5 from the plot of $\log \mathrm{Rp}$ versus $\log$ [PTC]. The plot of Rp versus [PTC] ${ }^{0.5}$ was found to be linear passing through the origin confirming the above results which is shown in Fig 11. In the absence of PTC it has been observed that there was no polymerization reaction even after several hours.

In the present case a slight decrease in rate of polymerization which is observed as the concentration reached maximum may be attributed to steric hindrance of bulky benzyl group in the catalyst. This bulky group would have hampered the effective transfer of anion to the organic phase at higher concentrations. At higher concentration of the catalyst there will be interaction of the positively charged carbonyl carbon and the negatively charged oxygen atom with anion and cation of another catalyst molecule and this may also offer steric resistance for the transfer of anion to the growing chain. Therefore the rate does not increase beyond a limit due to which leveling off tendency is observed. 


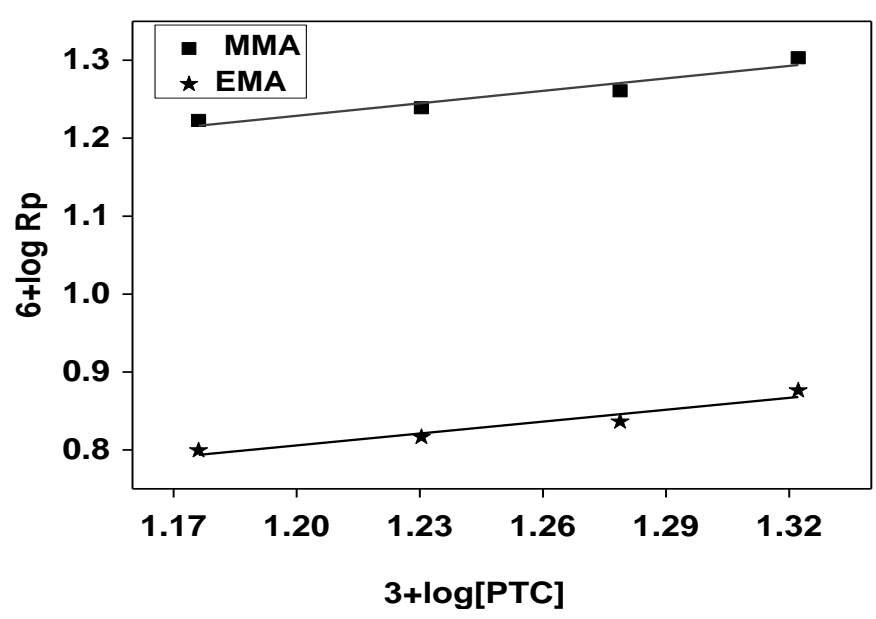

Figure 10. Effect of [PTC] on Rp

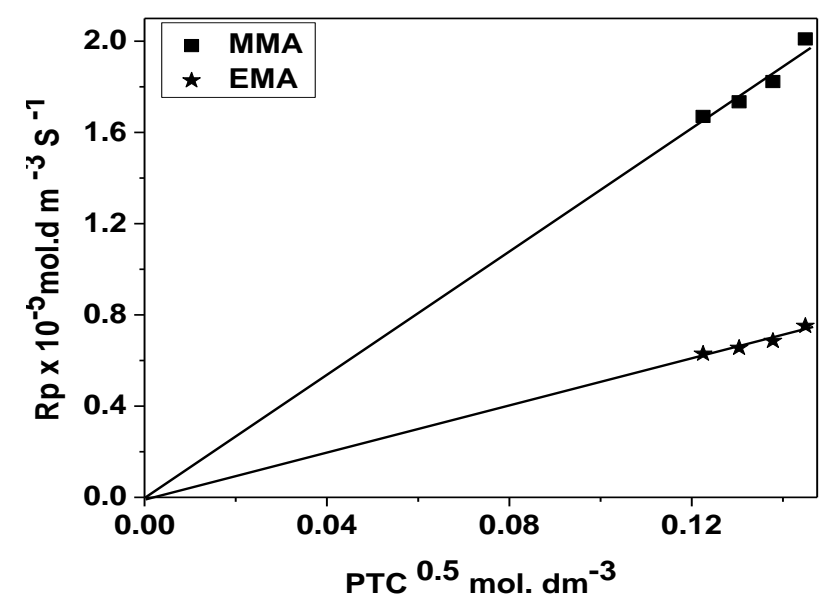

Figure 11. Plot of $[\mathrm{PTC}]^{0.5} \mathrm{VsRp}$

\section{Effect of variation of temperature on $R p$}

The influence of temperature in the range 50 to $65^{\circ} \mathrm{C}$ on the rate of polymerization was studied at fixed concentration of monomer, initiator, catalyst, acid strength and ionic strength. Rp increased with increase in temperature as shown in Table 5. The activation energy for the overall rate of polymerization has been calculated from the slope of Arrhenius plot of log Rpverses $1 / \mathrm{T}$ as shown in Fig 12, based on the value of activation energy, the other thermodynamic parameters were computed in Table 6.

Table 5. Effect of Temperature on Rp in RMA-BEDDAB$\mathrm{K}_{2} \mathrm{~S}_{2} \mathrm{O}_{8}$ [Monomer] $=2.0 \mathrm{~mol} \mathrm{dm}^{-3} ;$ [BEDDAB] $=1.0 \times 10^{-1} \mathrm{~mol}$ $\mathrm{dm}^{-3} ;\left[\mathrm{H}_{2} \mathrm{SO}_{4}\right]=0.2 \mathrm{~mol} \mathrm{dm}^{-3} ;\left[\mathrm{NaHSO}_{3}\right]=0.5 \mathrm{~mol} \mathrm{dm}^{-3} ;$ [PDS] $=2.0 \times 10^{-2} \mathrm{~mol} \mathrm{dm}^{-3}$;

\begin{tabular}{|c|c|c|c|c|c|c|}
\hline $\begin{array}{l}\mathrm{T}, \\
\mathrm{K}\end{array}$ & $\begin{array}{c}\mathrm{Rp} \times 10^{-5} \mathrm{~mol} \\
\mathrm{dm}^{-3} \mathrm{~S}^{-1} \\
\mathrm{MMA}\end{array}$ & $\begin{array}{c}\mathrm{Rp} \times 10^{-} \\
{ }^{5} \mathrm{~mol} \mathrm{dm}^{-3} \mathrm{~S}^{-} \\
{ }^{1} \mathrm{EMA}\end{array}$ & $\begin{array}{c}1 / \mathrm{T} \times \\
10^{-3}, \mathrm{~K} \\
1\end{array}$ & $\begin{array}{c}6+\log \\
\text { Rp MMA }\end{array}$ & $\begin{array}{c}6+\log \\
\text { Rp EMA }\end{array}$ & $\begin{array}{l}\mathrm{T}, \\
\mathrm{K}\end{array}$ \\
\hline 323 & 1.5614 & 0.5124 & 3.095 & 1.1935 & 0.7096 & 323 \\
\hline 328 & 1.7770 & 0.6284 & 3.048 & 1.2497 & 0.8184 & 328 \\
\hline 333 & 1.8719 & 0.6774 & 3.003 & 1.2723 & 0.8308 & 333 \\
\hline 338 & 1.9414 & 0.7067 & 2.958 & 1.2881 & 0.8492 & 338 \\
\hline
\end{tabular}

Table 6. Thermodynamic Parameters for RMA-BEDDAB$\mathrm{K}_{2} \mathrm{~S}_{2} \mathrm{O}_{8}$

\begin{tabular}{|l|c|c|c|c|}
\hline RMA & $\mathrm{Ea}, \mathrm{kJ} \mathrm{mol}^{-1}$ & $\Delta \mathrm{H}, \mathrm{kJ} \mathrm{mol}^{-1}$ & $\Delta \mathrm{S}, \mathrm{J} \mathrm{mol}^{-1} \mathrm{~K}^{-1}$ & $\Delta \mathrm{G}, \mathrm{kJ} \mathrm{mol}^{-1}$ \\
\hline MMA & 12.97 & 10.15 & -152.86 & 61.05 \\
\hline EMA & 18.21 & 16.28 & -143.03 & 63.91 \\
\hline
\end{tabular}

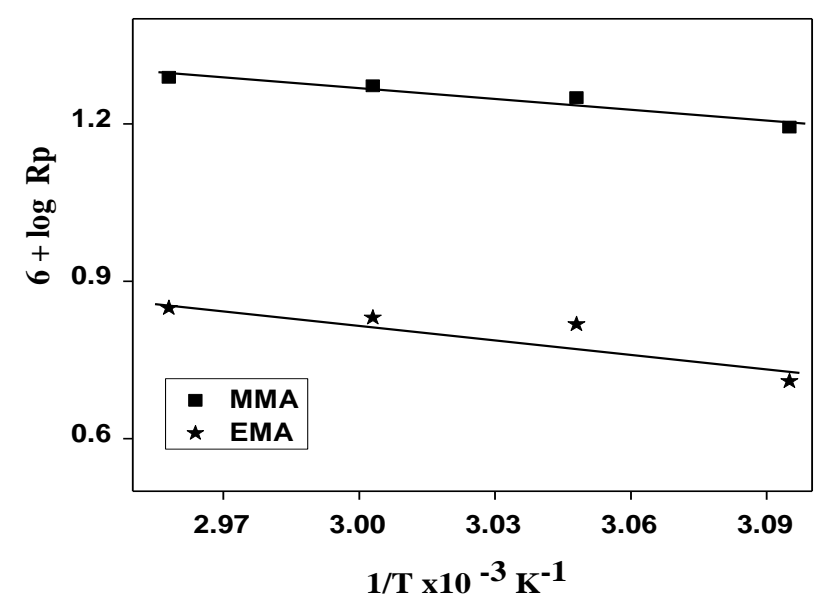

Figure 12. Arrhenius plot of MMA and EMA

The value of activation energy for the polymerization of methyl methacrylate is lower than that of ethyl methacrylate which is evident from the higher rate of polymerization of methyl methacrylate than that of ethyl methacrylate.

\section{Product Analysis}

The FT-IR spectra of the products obtained by phase transfer polymerization of MMA and EMA show the disappearance of the peak at $1635 \mathrm{~cm}^{-1}$ which is originally present in the FT-IR spectrum of the monomers which suggests that the olefinic double bond is involved in the polymerization and the product is polymethyl methacrylate and ethyl methacrylate respectively.

The DSC curve of the product obtained from MMA shows an endoderm due the glass transition of poly (MMA) and the Tg value was found to be $106^{\circ} \mathrm{C}$. The value is comparable to the literature value for crystalline poly (MMA) $\left(105^{\circ} \mathrm{C}\right)$. The DSC curve of the product obtained from EMA shows an endotherm due the glass transition of poly (EMA) and the Tg value was found to be $65^{\circ} \mathrm{C}$. The $\mathrm{Tg}$ value of the polymer depends on tacticity and molecular weight

\section{Determination of Molecular Weight of \\ Polyalkylmethacrylates}

The molecular weight of polymers has been established by GPC technique. The number average molecular weight (Mn), weight average molecular weight (Mw) and the polydispersityindex(Mw/Mn) values are shown in Table 7. The molecular weight of polymer which has been synthesized by using BEDDAB at low concentration of monomer and fixed concentrations of initiator and PTC are denoted as poly(alkyl methacrylate-L) and those synthesized at higher concentration of monomer and fixed concentrations of initiator and PTC are denoted as poly(alkyl methacrylate-H). 
Table 7. Dependence of Mol. Wt. on [RMA] in RMABEDDAB- $\mathrm{K}_{2} \mathrm{~S}_{2} \mathrm{O}_{8}$

\begin{tabular}{|c|c|c|c|}
\hline Polymer & $\mathrm{M}_{\mathrm{n}}$ & $\mathrm{M}_{\mathrm{w}}$ & $\mathrm{M}_{\mathrm{w}} / \mathrm{M}_{\mathrm{n}}$ \\
\hline PMMA-L & 26865 & 50770 & 1.89 \\
\hline PMMA-H & 41205 & 75405 & 1.83 \\
\hline PEMA-L & 15810 & 29270 & 1.85 \\
\hline PEMA-H & 34150 & 62155 & 1.82 \\
\hline
\end{tabular}

The poly index values of both poly methyl methacrylate and poly ethyl methacrylate suggest that the chain termination takes place predominantly by disproportionation [29, 30]. The Molecular weight of poly methyl methacrylate formed is found to be greater than that of poly ethyl methacrylate. As the rate of polymerization of methyl methacrylate is found to be greater than that of ethyl methacrylate this trend may be observed which is attributed to the difficulty in the chain propagation in the polymerization of ethyl methacrylate than methyl methacrylate. Molecular weight of the polymers increased as the concentration of the monomers increased.

\section{Kinetic Scheme and Mechanism}

Scheme 2 represents the kinetic investigation of the polymerization of alkylmethacrylates(M) initiated by $\mathrm{K}_{2} \mathrm{~S}_{2} \mathrm{O}_{8}$ / PTC in ethyl acetate / water biphase system.

The subscripts (w) and (o) represent aqueous and organic phases. $k_{i}, k_{p}$ and $k_{t}$ refer to the rate of initiation, rate of propagation and rate of termination and $\mathrm{Q}$ represent phase transfer catalyst.

Phase transfer

$$
\begin{aligned}
& \underset{(\mathrm{w})}{2 \mathrm{Q}^{+}}+\underset{(\mathrm{w})}{\mathrm{S}_{2} \mathrm{O}_{8}^{2-}} \stackrel{\mathrm{K}}{\rightleftharpoons}\left(\mathrm{Q}^{+}\right)_{2}\left(\mathrm{~S}_{2} \mathrm{O}_{(\mathrm{o})}{ }^{-}\right) \\
& \left(\mathrm{Q}^{+}\right)_{2}\left(\mathrm{~S}_{2} \mathrm{O}_{8}^{2^{-}}\right) \stackrel{\mathrm{k}_{\mathrm{d}}}{\longrightarrow} 2 \mathrm{Q}^{+} \mathrm{SO}_{4}^{\bullet-} \\
& \text { (o) (o) } \\
& 2 \mathrm{Q}^{+} \mathrm{SO}_{4}^{\bullet-}+\mathrm{M} \stackrel{\mathrm{k}_{\mathrm{i}}}{\longrightarrow} \mathrm{M}_{1}^{\bullet}\left(\mathrm{M}-\mathrm{O}-\mathrm{SO}_{3}^{-} \mathrm{Q}^{+}\right)
\end{aligned}
$$$$
\text { (o) }
$$

$$
\text { (o) }
$$

(o)

InitiationPropagation

$$
\begin{gathered}
\mathrm{M}_{1}^{0}+\mathrm{M} \stackrel{\mathrm{k}_{\mathrm{p}}}{\longrightarrow} \mathrm{M}_{2}^{\bullet} \\
\mathrm{M}_{\mathrm{n}-1}^{\bullet}+\mathrm{M} \stackrel{\mathrm{k}_{\mathrm{p}}}{\longrightarrow} \mathrm{M}_{\mathrm{n}}
\end{gathered}
$$

Termination

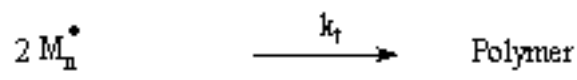

Based on the mechanism the rate of polymerization for RMA catalyzed using BEDDAB has been derived as

$$
R p=k_{p}\left[\frac{k_{d} K}{k_{t}}\right]^{1 / 2} \frac{[M]\left[S_{2} O_{\mathrm{g}}{ }^{2-}\right]^{1 / 2}\left[Q^{+}\right]_{\text {total }}}{1+K\left[Q^{+}\right]_{W}\left[S_{2} O_{\mathrm{g}}{ }^{2-}\right]_{W}}(7)
$$

The above equation satisfactorily explains all the experimental results and observations. The increase in $\mathrm{Rp}$ with increase in [PTC] and $\left[\mathrm{K}_{2} \mathrm{~S}_{2} \mathrm{O}_{8}\right]$ may be due to anincrease in the amount of $\mathrm{Q}_{2} \mathrm{~S}_{2} \mathrm{O}_{8}$ transferred to the organic phase, which in turn increase the number of $\mathrm{SO}_{4}{ }^{-}$radical ions.

\section{Conclusion}

A new single site phase transfer catalyst, 2benzoylethyldecyldimethylammonium bromide was prepared and characterized using spectroscopic techniques. The kinetics of free radical polymerization of alkyl methacrylate initiated by $\mathrm{K}_{2} \mathrm{~S}_{2} \mathrm{O}_{8}$ was studied using newly synthesized single site PTC in ethylacetate / water biphase media under inert condition. Rate of polymerization was evaluated atdifferent concentration of monomer, initiator, PTC and temperature. The order with respect to monomer was found to be 0.5 and around unity with respect to initiator, half order with respect to single site PTC. Based on the results obtained a suitable kinetic mechanism has been proposed. Molecularweight of PMMA was found to be high at higher concentration of monomer and at fixed concentrations of initiator and PTC. The formation of polymers was confirmed by FT-IR analysis.

\section{References}

[1] C. M. Starks, C. Liotta, and M. Halpem, Phase transfer catalysis: Fundamentals, applications and industrial perspectives, Chapman and Hall, New York, Chap. 1, 1994.

[2] E. V. Dehmlow, andS. S. Dehmlow, Phase transfer catalysis, $\quad 3^{\text {rd }}$ ed., VerlagChemie, Weinheim, Germany, Chap. 1, 1993.

[3] C. M. Starks, and C. Liotta, Phase transfer catalysis: Principles and techniques, Academic Press, New York, and Chap. 1, 1978.

[4] M. Makosza, "Two-Phase reactions in the chemistry of carbanions and halocarbenes: A useful tool in organic synthesis, 'Pure Appl. Chem. Soc., vol. 43, pp. 439-447, 1975.

[5] M. J. Umapathy, and T. Balakrishnan, "Kinetics and mechanism of polymerization of methyl methacrylate initiated by phase transfer catalyst-ammonium perdisulfate system, ”J., Polym. Mater, vol. 15, pp. 275-278, 1998.

[6] M. J. Umapathy, and D. Mohan, "Studies on phase transfer catalysed polymerization of acrylonitrile," Hung. J. Ind. Chem., 27, pp. 245-250, 1999

[7] M. J. Umapathy, andD. Mohan, "Studies on phase transfer catalysed polymerization of glycidyl methacrylate, " J. Polym. Mater, vol. 16, pp. 167171, 1999

[8] M. J. Umapathy, R. Malaisamy, and D. Mohan, "Kinetics and mechanism of phase transfer catalysed free radical polymerization of methyl acrylate, "J. Macromol. Sci., Pure Appl. Chem., vol. 37, pp. 1437-1445, 2000.

[9] M. J. Umapathy, andD. Mohan, "Phase transfer catalysed polymerization of butyl methacrylate using potassium peroxydisulphate as initiator-a kinetic study, ’Ind J Chem Tech., vol. 8, pp. 510-514, 2001.

[10] T. Sivaramakrishnan, and K. S. Yoganand, "Phase Transfer Catalyst Assisted Free Radical Polymerization of Styrene-A Kinetic Study, 'IJACSA, vol. 3, pp. 56-59, 2015. 
[11] M. Dharmendira Kumar, P. KonguvelThehazhnan, M. J. Umapathy, andM. Rajendran, "Free radical polymerization of methyl methacrylate in the presence of phase transfer catalyst-a kinetic study, " Int. J. Polym. Mater, vol. 53, pp. 95-103, 2004.

[12] S. Savitha, M. Vajjiravel, and M. J. Umapathy, "Polymerization of butyl acrylate using potassium peroxydisulphate as initiator in the presence of phase transfer catalyst-a kinetic study, "Int. J. Polym. Mater. vol. 55, pp. 537-548, 2006.

[13] M. Vajjiravel, and M. J. Umapathy, "Free radical polymerization of methyl methacrylate initiated by multi-site phase transfer catalyst-a kinetic study, " Colloid Polym. Sci., 286, pp. 729-738, 2008.

[14] J. Usha, P. Shyamalavathy, and M. J. Umapathy, "Free Radical Polymerization of Acrylonitrile Using Potassium PeroxyDisulphate Initiator and a Phase Transfer Catalyst, ’Int. J. Polym. Mater, vol. 58, pp. 99-110, 2009.

[15] P. A. Vivekanand, and T. Balakrishan, "Kinetics of dichlorocyclopropanation of vinylcyclohexane catalyzed by a new multi-site phase transfer catalyst, "Catal. Commun., vol. 10, no. 5, pp. 687-692, 2009.

[16] K. Mohammed Mustaque, S. Jayakumar, and T. K. Shabeer. "Phase transfer catalysis: Kinetics of acrylonitrile polymerization initiated by potassium peroxomonosulfate-cetylpyridinium chloride system, "J. chem. biol. phys. sci., vol. 2, pp. 601-607, 2012.

[17] G. Thangaraj, A. Ramu, and R. SayeeKannan, "Kinetics and mechanisms of phase transfer catalyst aided free radical polymerization of acrylonitrile initiated by peroxydiphophatetetraethylammonium chloride under biphase condition, " J. chem. biol. phys. sci., vol. 14, no. 4, pp. 3011-3014, 2014.

[18] A. I. Vogel, Text book of practical organic chemistry, $5^{\text {th }}$ edn. Longmans, London, Chap. 6, 1989.

[19] G. M. Burnett, P. Evans, andH. W. Melville, "Polymerization of esters of methacrylic acid. Part Ithe polymerization of n-butyl methacrylate, "Trans. Faraday Soc., 49, pp. 1096-1104, 1953.

[20] G. M. Burnett, P. Evans, and H. W. Melville, "Polymerization of esters of methacrylic acid. Part 2. - the polymerization of n-propyl methacrylate, " Trans. Faraday Soc., vol. 49, pp. 1105-1107, 1953.

[21] G. M. Burnett, G. G. Cameron, and M. M Zafar, "Polymerization of methyl methacrylate in solution, " Eur. Polym. J, vol. 19, pp. 823-830, 1970.

[22] T. Balakrishnan, and N. Jayachandramani, "Phase transfer catalysis-free radical polymerization of methyl methacrylate using $\mathrm{K}_{2} \mathrm{~S}_{2} \mathrm{O}_{8}$-quaternary ammonium salt catalyst system-A kinetic study, ” J. Macromol. Sci. Part A Pure Appl. Chem., vol. 31, no. 7, pp. 847-857, 1994.

[23] M. Vajjiravel, and M. J. Umapathy, "Multi-site phase transfer catalyst assisted radical polymerization of glycidyl methacrylate using potassium peroxydisulphate as initiator-a kinetic study, " J. Polym. Res., vol. 15, 235-240, 2008.
[24] M. Ueda, S. Shouji, T. Ogata, M. Kamachi, and C. U. Pittman, "Radical initiated homo and copolymerization of $\alpha$-fluoroacrylamide living radicals in homogeneous system, " Macromolecules, vol. 17, pp. 2800-2804, 1984.

[25] P. D. Bartlett, and J. D. Catman, "The kinetics of the decomposition of potassium persulfate in aqueous solutions of methanol, " J. Am. Chem. Soc., vol. 71, pp. 1419-1425, 1949.

[26] I. M. Kolthaff, and I. K Miller, "The chemistry of persulfate. The kinetics and mechanism of the decomposition of the persulfate ion in aqueous medium, " J. Am. Chem. Soc., vol. 73, pp. 30553059, 1951.

[27] A. Jayakrishnan, and D. O. Shah, "Phase transfer catalyzed free radical polymerization:Kinetics of polymerization of methyl methacrylate using ammonium peroxydisulfate/hexadecylpyridinium chloride in ethyl acetate/water, "J. Polymer Sci. Polymer Chem. Ed., vol. 21, pp. 3201-3208, 1983.

[28] T. Balakrishnan, andS. Damodar Kumar, "Phase transfer catalysis: Free radical polymerization of acrylonitrile using peroxomonosulphatetetrabutylphosphonium chloride catalyst system: A kinetic study," J. Appl. Polym. Sci., vol. 76, pp. 1564-1571, 2000.

[29] H. W. Melville, B. Noble, andW. F. Watson, "Copolymerization. II. Molecular weight distribution and mean molecular weights in copolymerization," J. Polym. Sci., vol. 4, pp. 629-637, 1949.

[30] S. Teramachi, A. Hasegava, M. Akatsuka, A. Yamashita, and N. Takemoto, "Molecular Weight Distribution and Correlation between Chemical Composition and Molecular Weight in a HighConversion Copolymer of Styrene-Methyl Acrylate, "Macromolecules, vol. 11, no. 6, pp. 1206-1210, 1978. 